\title{
Vibration Test and Comfort Analysis of Environmental and Impact Excitation for Wooden Floor Structure
}

\author{
Yewei Ding, ${ }^{\mathrm{a}}$ Yifan Zhang, ${ }^{\mathrm{a}}$ Zheng Wang, ${ }^{\mathrm{a}, *}$ Zizhen Gao, ${ }^{\mathrm{a}}$ Tongyue Zhang, ${ }^{\mathrm{a}}$ and \\ Xiuling Huang ${ }^{b}$
}

\begin{abstract}
To meet consumer requirements for comfort in wooden structure construction, test mode methods (the environmental excitation method and impact excitation method) have been used to test six measuring points of the flooring in a two-story residential light-wood structure. The following tests were performed: the fundamental frequency test of floor structure under environmental excitation mode; the ball excitation dynamic vibration test of single and rhythmic running of a basketball and tennis ball under impact excitation mode; and the pedestrian dynamic vibration test of jump, single-step, steady walking, and rhythmic movement. The comfort analysis was validated based on the test results of peak value and effective value of fundamental frequency, acceleration, and speed. ANSYS was used to verify the calculation mode of the floor structure. Research showed that the fundamental frequencies of the building structure obtained through the calculation mode and the test mode were consistent, and both were higher than $4.5 \mathrm{~Hz}$. The maximum measured acceleration peak value under the impact excitation mode was $407.2 \mathrm{~mm} / \mathrm{s}^{2}$. The maximum speed peak value was $5.606 \mathrm{~mm} / \mathrm{s}$. The maximum acceleration effective value (RMS) was less than $450 \mathrm{~mm} / \mathrm{s}^{2}$. The floor structure results met the building comfort requirements. The research has value in engineering applications, as it advances understanding concerning the vibration characteristics and comfort optimization of light-wood frame construction.
\end{abstract}

Keywords: Wooden floor structure; Environmental excitation; Impact excitation; Vibration test; Natural frequency; Comfort analysis

Contact information: a: College of Materials Science Engineering, Nanjing Forestry University, Nanjing, China 210037; b: College of Mechanical and Electronic Engineering, Nanjing Forestry University, Nanjing, China 210037; *Corresponding author: wangzheng63258@ 163.com

\section{INTRODUCTION}

With improved living standards, people have increased demands for building comfort. The floor, roof, and shear wall are the three main structural systems of light-wood frame construction, and all influence comfort. As the most common structural system, the wooden floor is also a system that often has physical contact with the occupants (Yang et al. 2019). The vibration frequency of the wooden floor structure is generally above $8 \mathrm{~Hz}$. Usually wooden buildings have a small number of floors and a small area, and there are fewer events causing safety problems due to its low natural frequency. However, because of the defects or deficiencies in the floor structural performance, the dynamic movement of people or objects in the living environment may cause discomfort to the occupants. Movements, such as walking, running, jumping, falling, etc., easily cause structural vibration in a wooden floor, which will seriously affect work efficiency and living quality in severe cases (Zhang and Xie 2011). The frequency range that has obvious influence on the human body is generally between 0 and $50 \mathrm{~Hz}$. The wooden floor can be regarded as a 
continuum, and its vibration frequency is infinite. Due to its inherent structural dynamic characteristics, it is necessary to perform the building comfort analysis using the on-site dynamic vibration performance testing according to the structural dynamic principle (Wang et al. 2019a).

Researchers worldwide have made abundant research achievements on floor vibration. Jarnerö et al. (2015) tested natural frequency and damping ratio of prefabricated wooden floor units under different construction stages and different boundary constraints in the laboratory. The results show that under different states, the tested damping ratios are notably different. Rijal et al. (2016) conducted a modal test on a wooden floor with 6- and 8-m-span beams, and analyzed its natural frequency, damping ratio, and vibration mode. Their results show a good correlation between the test values and predicted values.

In China, the research on floor vibration is mainly based on concrete structures and steel structures. The specification JGJ 3-2010 (2010), "Technical specification for highrise building concrete structures," proposed that the vertical vibration frequency of floor structures should not be less than $3 \mathrm{~Hz}$, and stipulated the recommended limits for values of vertical vibration acceleration, floor structure acceleration caused by human walking, and vibration acceleration caused by rhythmic running. The "Code for design of concrete structures" or GB 50010-2010 (2015) stipulates that the vertical natural vibration frequency of concrete floor structures, such as residences and apartments, shall not be lower than 5 Hz. The "Code for design and construction of composite floor slab" or CECS 273-2010 (2010) specifies the limit of the peak value of vibration acceleration.

Although research in China concerning modern wood frame construction started late, it has developed rapidly in recent years, and preliminary research results have been obtained regarding wooden floor vibration. Zhou (2006) summarized the research progress on the relevancy of the design method on wooden floor vibration, and noted the problems with current design development and point out the direction of further research. Lu et al. (2010) analyzed the vibration acceleration response of floor structures with pedestrian load, and proposed an analysis method using the frequency-weighted root mean square value of acceleration as the evaluation index. Lu et al. also analyzed the variation between the law of the vertical vibration intensity and the fundamental frequency. On the basis of domestic and foreign research, Huang et al. (2011) proposed a comfort design standard considering the rhythmic running and derived a formula of vibration acceleration according to the dynamic principle. They also elaborated in detail the load value determination and the analysis of the working conditions of the floor structure vibration calculation. These results can provide reference for the vibration comfort design of the floor under the action of rhythmic running. $\mathrm{Li}$ (2012) studied the three-story large-span cantilevered floor of Dalian Citizen Fitness Center for comfort analysis and vibration control under the action of human activities. The dynamic response of the large-span cantilevered floor under the crowd load was calculated and evaluated by using SAP2000 through a different model: a single-step load model, a single person continuous walking, a rhythmic running load model, and a random load model. The floor structure vibration was controlled by the design of reasonably tuned mass damper (TMD) parameters.

In view of the entire introduction, the current paper conducted a fundamental frequency test on a floor structure under environmental excitation mode; the ball excitation dynamic vibration test of single and rhythmic running of basketball and tennis under impact excitation mode; and the pedestrian dynamic vibration test of a single-step, jumping, steady walking, and rhythmic running based on the floor structure of a two-story assembled lightwood structure residence (Wang et al. 2019b). The comfort analysis was validated based 
on the test results of peak value and effective value of fundamental frequency, acceleration, and speed. This research is valuable to meet people's objective requirements for building comfort, and to provide reference for the design optimization of wooden floor structures.

\section{EXPERIMENTAL}

\section{Materials}

\section{Test object}

A two-story light-wood frame construction (a structure for tool storage) was used for testing. Its external dimensions were $6100 \mathrm{~mm}$ long $\times 2576 \mathrm{~mm}$ wide $\times 3396 \mathrm{~mm}$ high, and its internal dimensions were $6042 \mathrm{~mm}$ long $\times 2460 \mathrm{~mm}$ wide $\times 3230 \mathrm{~mm}$ high. The external dimensions of the floor structure as the test object are shown in Table 1 and Fig. 1. All materials of the wooden floor structure were fixed by nailing.

Table 1. Wooden Floor Structure Composition

\begin{tabular}{|c|c|c|c|}
\hline Material & $\begin{array}{c}\text { Specification }(\mathrm{mm} \times \\
\mathrm{mm} \times \mathrm{mm})\end{array}$ & $\begin{array}{c}\text { Average } \\
\text { Density } \\
\left(\mathrm{g} / \mathrm{cm}^{3}\right)\end{array}$ & $\begin{array}{c}\text { Average Moisture } \\
\text { Content (\%) }\end{array}$ \\
\hline Oriented strand board (OSB) & $2440 \times 1220 \times 10$ & 0.57 & 7 \\
\hline $\begin{array}{c}\text { Joint spruce-pine-fir (SPF) } \\
\text { lumber }\end{array}$ & $5000 \times 89 \times 39$ & 0.44 & 12 \\
\hline Maple hardwood floors & $600 \times 84 \times 17.6$ & 0.78 & 11 \\
\hline Portuguese cork board & $950 \times 640 \times 20$ & 0.15 & 6 \\
\hline
\end{tabular}
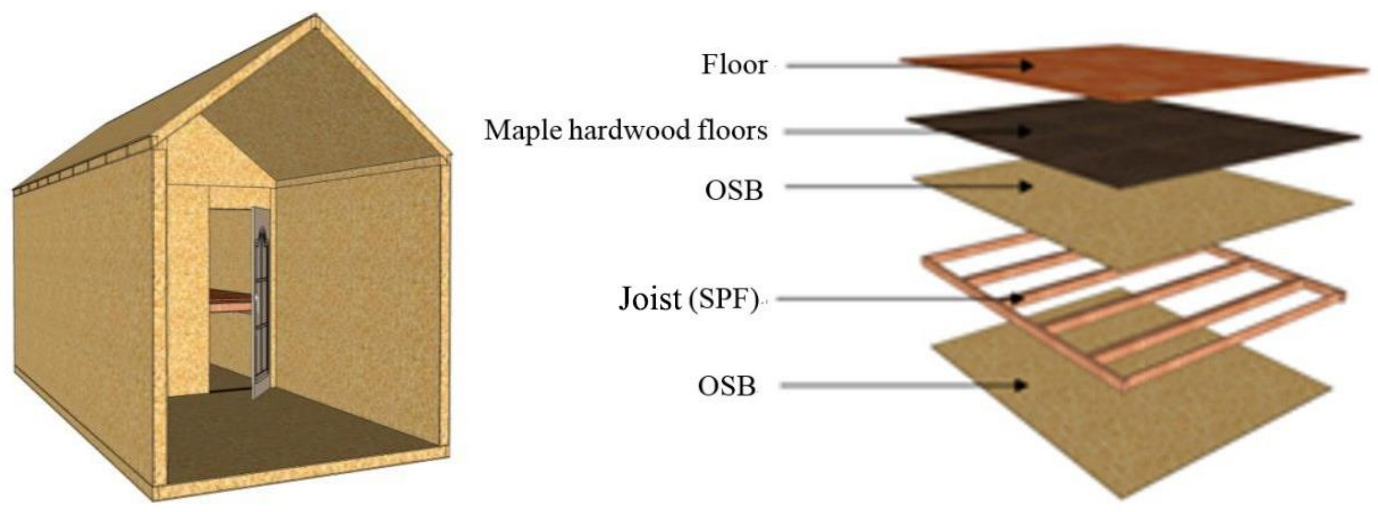

Fig. 1. Schematic diagram of wooden floor

\section{Instruments and accessories}

(1) The vibration and dynamic signal acquire analysis system (CRAS) and dynamic signal acquisition and analysis system of Nanjing Anzheng Software Engineering Co., Ltd. (Nanjing, China), were used. They primarily included a signal acquisition box, a signal conditioning box, a working station installed with AdCRAS analysis software (Version 8.0, Nanjing, China), SsCRAS analysis software (Version 8.0, Nanjing, China), and Origin Pro software (Version 9.0, Northampton, MA, USA). The system had acquisition and 
analysis functions, including data acquisition, signal analysis, system analysis, noise analysis, and modal analysis, which were realized by dedicated software.

(2) Four 941B vibrators of the Institute of Engineering Mechanics of the China Earthquake Administration (Wuhan, China) were used. Each vibrator's size was $63 \mathrm{~mm} \times$ $63 \mathrm{~mm} \times 80 \mathrm{~mm}$, with a weight of $1 \mathrm{~kg}$. The acceleration gear (maximum measuring range $20000 \mathrm{~mm} / \mathrm{s}^{2}$ ) and second speed gear (maximum measuring range was $125 \mathrm{~mm} / \mathrm{s}$, displacement $20 \mathrm{~mm}$ ) were adopted.

(3) Other accessories, such as steel tape, double-sided tape, etc. were also used.

\section{Calculation mode}

Mechanical performance test of base material of floor cover

Seven samples of OSB board, maple floor and SPF each with an average moisture content of $12 \%, 9 \%$ and $12 \%$ were randomly selected to test the elastic modulus, shear modulus, and Poisson's ratio (Wang et al. 2018). Table 2 shows the mechanical properties of the tested materials.

Table 2. Material Mechanical Properties

\begin{tabular}{|c|c|c|c|}
\hline & OSB & SPF & Maple \\
\hline$E_{x} / G P a$ & 6.4 & 11.6 & 12.6 \\
\hline$E_{y} / G P a$ & 2.7 & 0.5 & 1.42 \\
\hline$E_{z} / G P a$ & 2.7 & 0.9 & 0.68 \\
\hline$G_{x y} / G P a$ & 2.5 & 0.72 & 1.36 \\
\hline$G_{y z} / G P a$ & 0.75 & 0.04 & 0.29 \\
\hline$G_{x z} / G P a$ & 0.77 & 0.75 & 0.98 \\
\hline$\mu_{x y}$ & 0.23 & 0.47 & 0.69 \\
\hline$\mu_{y z}$ & 0.12 & 0.25 & 0.47 \\
\hline$\mu_{x z}$ & 0.33 & 0.37 & 0.60 \\
\hline$\rho /\left(\mathrm{kg} / \mathrm{m}^{3}\right)$ & 614 & 390 & 610 \\
\hline
\end{tabular}

\section{Building a floor model}

ANSYS software was used to model the fabricated light wood building floor. Based on simulation data required for the test, beam 188 and shell181 units were used to input the relevant parameters of floor structure to the model to obtain the vibration shape of the floor and its corresponding frequency. Figure 2 shows the finite element model of the floor.

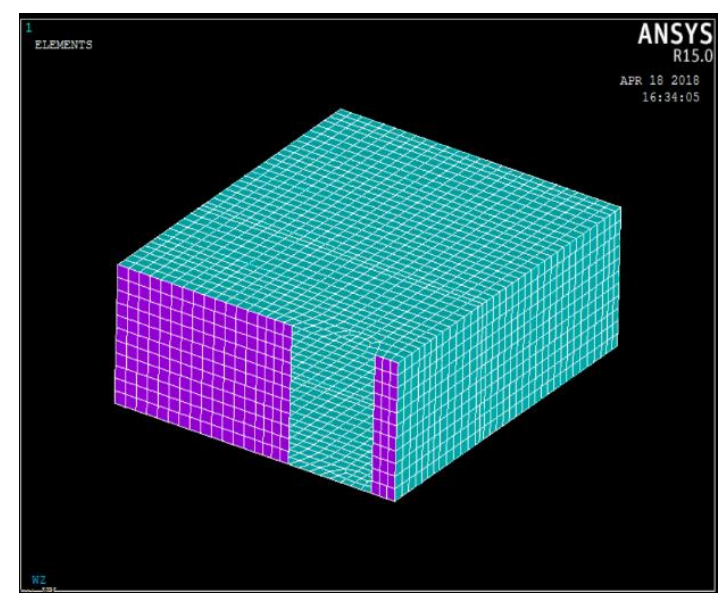

Fig. 2. Model of floor structure 


\section{Methods}

Environmental excitation test method - Test principle and test block diagram

The block diagram of the spectrum test of wooden floor is shown in Fig. 3 The vibrator placed on the wooden floor received the environmental vibration signal and converted it into an electrical signal output. After the signal conditioner amplified and filtered the electrical signal, the Analog-to-Digita (AD) analog signal was converted into a digital signal by the acquisition box. After analysis and processing by software, the natural frequency value spectrum of the wooden floor was obtained (ISO/AWI 2631-1 1997; ISO 2631-2 2003).

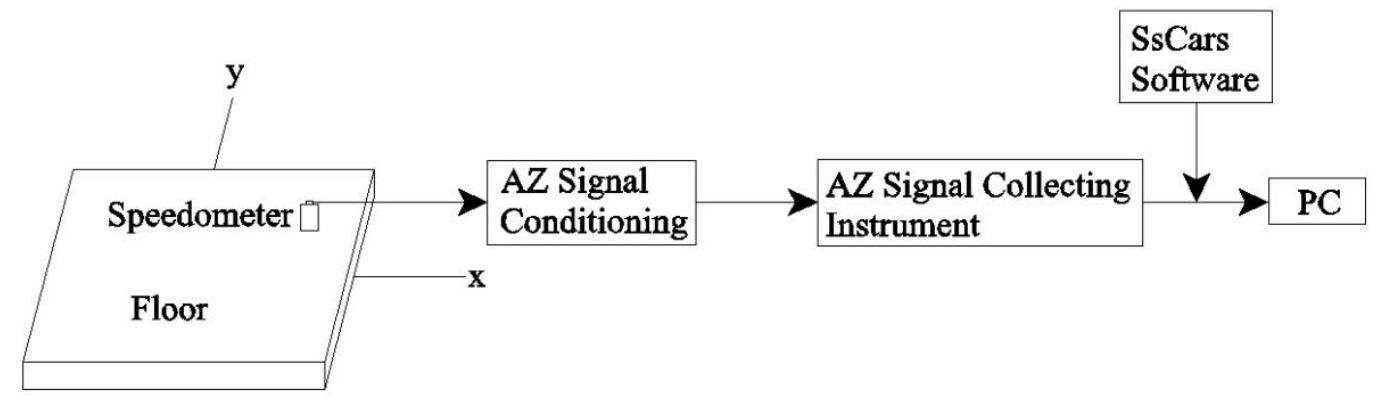

Fig. 3. Test block diagram of floor spectrum

\section{Main Test Steps}

(1) Test sites were selected. To obtain better fundamental frequency measured in the measuring point, six measuring points were used, and each measuring point was tested twice, as shown in Fig. 4.

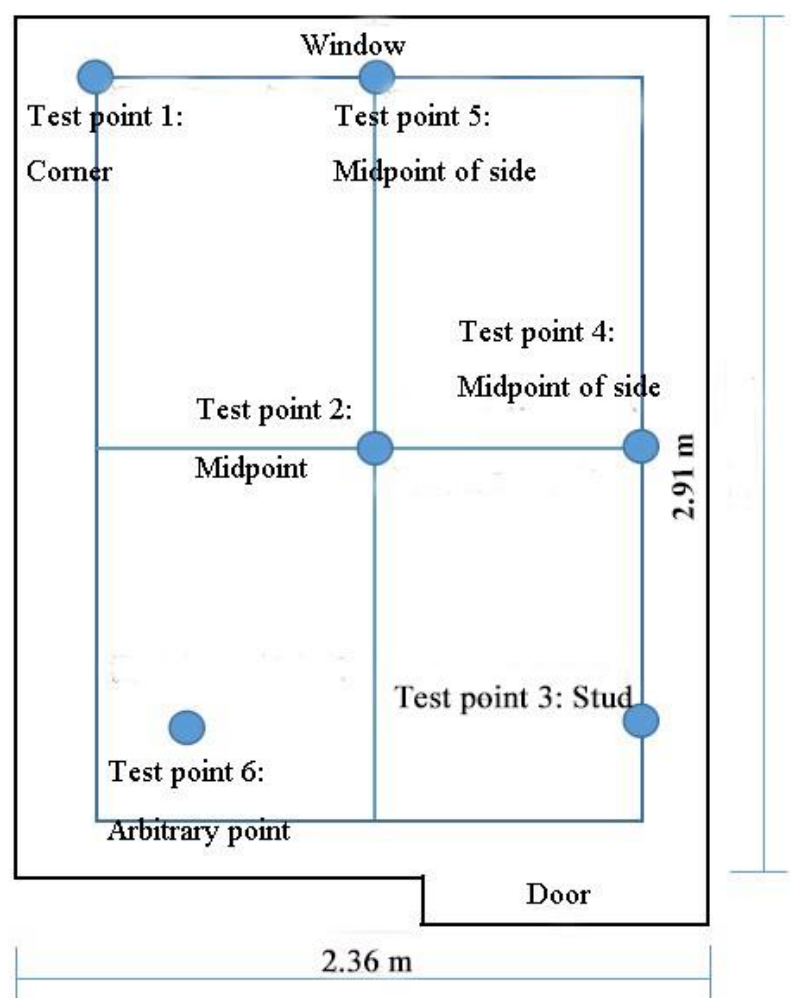

Fig. 4. Distribution of test points 
(2) The instrument was connected and the wiring checked. The vibrators were placed and fixed at six test points, and the second speed gear and acceleration gear were used.

(3) Parameters were set, and the oscillations began. The unit of the speedometer was $\mathrm{mm} / \mathrm{s}$, the environmental excitation mode was used in a voltage range between 0 and $1250 \mathrm{mV}$ and the analysis frequency of $50 \mathrm{~Hz}$, and the AdCras software was also used to oscillate, check, and adjust the amplification factor.

(4) Data was collected and the test was repeated twice.

\section{Impact Excitation Test Method}

Test principle and test block diagram

The test spectrum block diagram was the same as shown in Fig. 3. As shown, the vibrator placed on the wooden floor received an impact vibration signal and converted it into an electrical signal output. After the signal conditioner amplified and filtered the electrical signal, the acquisition box converted the analog signal AD into a digital signal. The natural frequency spectrum of the structure was obtained by software analysis.

\section{Ball excitation test method}

The ball excitation comprised of both a single-time excitation on the floor and regular knocks on the floor, the latter of which fell freely and regularly at a frequency of 2 $\mathrm{Hz}$ and a height of $1 \mathrm{~m}$ to test the acceleration peak, effective acceleration, speed peak, and effective speed.

\section{Pedestrian excitation test method}

(1) Jump excitation test

The main steps of the jump excitation test of the wooden floor (Lin 2015) were as follows: connect the vibration and dynamic signal acquisition and analysis system instruments, and check the wiring; respectively place the $941 \mathrm{~B}$ vibration absorbers at each measuring point on the wooden floor; set SsCras software parameters (the units of accelerometer and speedometer were $\mathrm{mm} / \mathrm{s}^{2}$ and $\mathrm{mm} / \mathrm{s}$, respectively, the analysis frequency was $50 \mathrm{~Hz}$ ); the tester with a weight of $60 \mathrm{~kg}$ was in the range of $100 \pm 30 \mathrm{~mm}$ at the test point, and oscillating was performed; the experimenter collected the frequency spectrum of the jump excitation test (the jumping height was $150 \mathrm{~mm}$ ). The test was repeated twice.

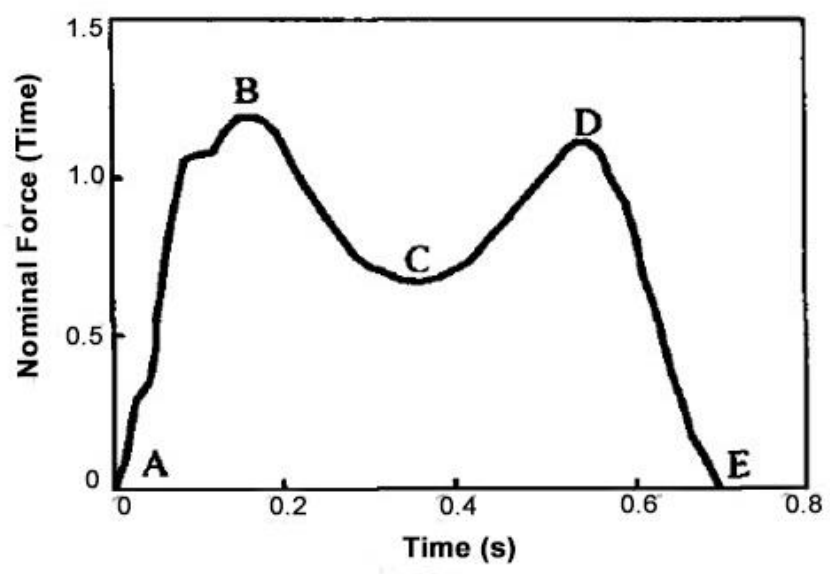

Fig. 5. Schematic diagram of single-step excitation 
(2) Single-step excitation test

Figure 5 shows the single-step excitation curve (Lin 2015), where the nominal force was the ratio of vertical force to human weight. The force at point B was 1.20 to 1.25 times the human weight, while the force at point D was approximately 1.15 times the human weight.

(3) Steady walk excitation test

The experimenter with a weight of $60 \mathrm{~kg}$ walked steadily at a frequency of $2 \mathrm{~Hz}$ on the wooden floor (Lou 2011).

(4) Rhythmic running excitation test

The experimenter with a weight of $60 \mathrm{~kg}$ ran steadily at a frequency of $4 \mathrm{~Hz}$ on the wooden floor (Xu et al. 2008).

\section{RESULTS AND DISCUSSION}

\section{Finite Element Simulation Results}

Through ANSYS modal analysis, the fundamental frequency of the overall building slab model was $16.413 \mathrm{~Hz}$. Figure 6 shows a bending mode and its corresponding frequency in the length and width directions of the floor.

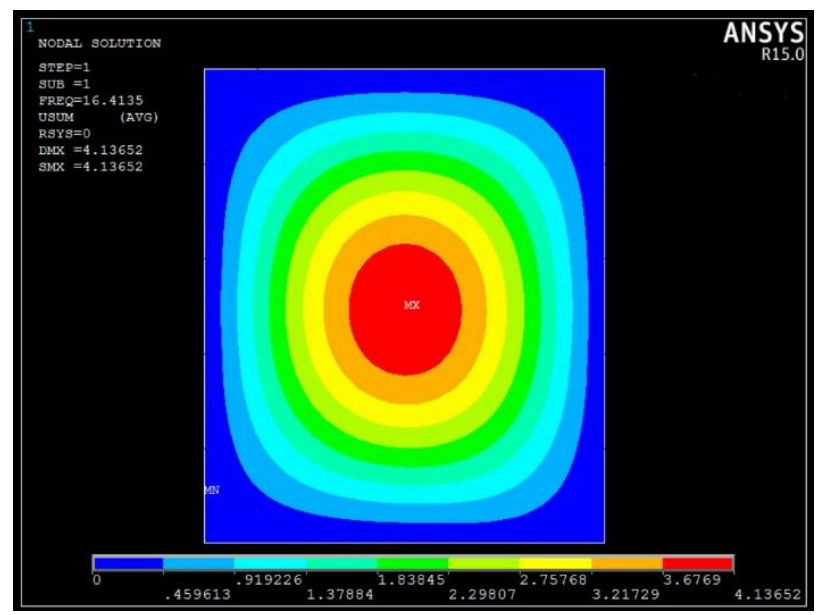

Fig. 6. The first-order vibration mode of floor model simulation

\section{Environmental Excitation Test Results}

Under environmental excitation mode, the fundamental frequency test results of measuring points 1 through 6 of the wooden floor were obtained, as shown in Table 3 . The mean value, standard deviation, and coefficient of variation were $17.50 \mathrm{~Hz}, 0.075$, and $0.04 \%$, respectively. 
Table 3. Environmental Excitation Test Results for Points 1 Through 6

\begin{tabular}{|c|c|c|c|c|c|c|}
\hline Testing Point Number & No. 1 & No. 2 & No. 3 & No. 4 & No. 5 & No. 6 \\
\hline Natural Frequency $(\mathrm{Hz})$ & 17.49 & 17.43 & 17.43 & 17.44 & 17.63 & 17.56 \\
\hline
\end{tabular}

\section{Impact Excitation Test Results}

\section{Ball excitation test results}

(1) Basketball single excitation test

The test results of the acceleration, speed, and fundamental frequency values of the single excitation test of a basketball at 1 through 6 are shown in Table 4 . Figure 7 is the spectrum diagram of point 2 .

Table 4. Acceleration, Speed, and Natural Frequency Values of a Single Excitation Test of a Basketball at Points 1 through 6

\begin{tabular}{|c|c|c|c|c|c|}
\hline & $\begin{array}{c}\text { Acceleration } \\
\text { Peak }\left(\mathrm{mm} / \mathrm{s}^{2}\right)\end{array}$ & $\begin{array}{c}\text { Acceleration } \\
\mathrm{RMS}\left(\mathrm{mm} / \mathrm{s}^{2}\right)\end{array}$ & $\begin{array}{c}\text { Speed } \\
\text { Peak } \\
(\mathrm{mm} / \mathrm{s})\end{array}$ & $\begin{array}{c}\text { Speed } \\
\mathrm{RMS} \\
(\mathrm{mm} / \mathrm{s})\end{array}$ & $\begin{array}{c}\text { Natural } \\
\text { Frequency } \\
(\mathrm{Hz})\end{array}$ \\
\hline Average & 398.9 & 53.91 & 5.542 & 0.629 & 16.53 \\
\hline Maximum & 399.1 & 57.04 & 5.545 & 0.676 & 16.75 \\
\hline Standard Deviation & 0.15 & 2.05 & 0.00 & 0.04 & 0.15 \\
\hline Coefficient of Variation & 0.00 & 0.04 & 0.00 & 0.06 & 0.01 \\
\hline
\end{tabular}

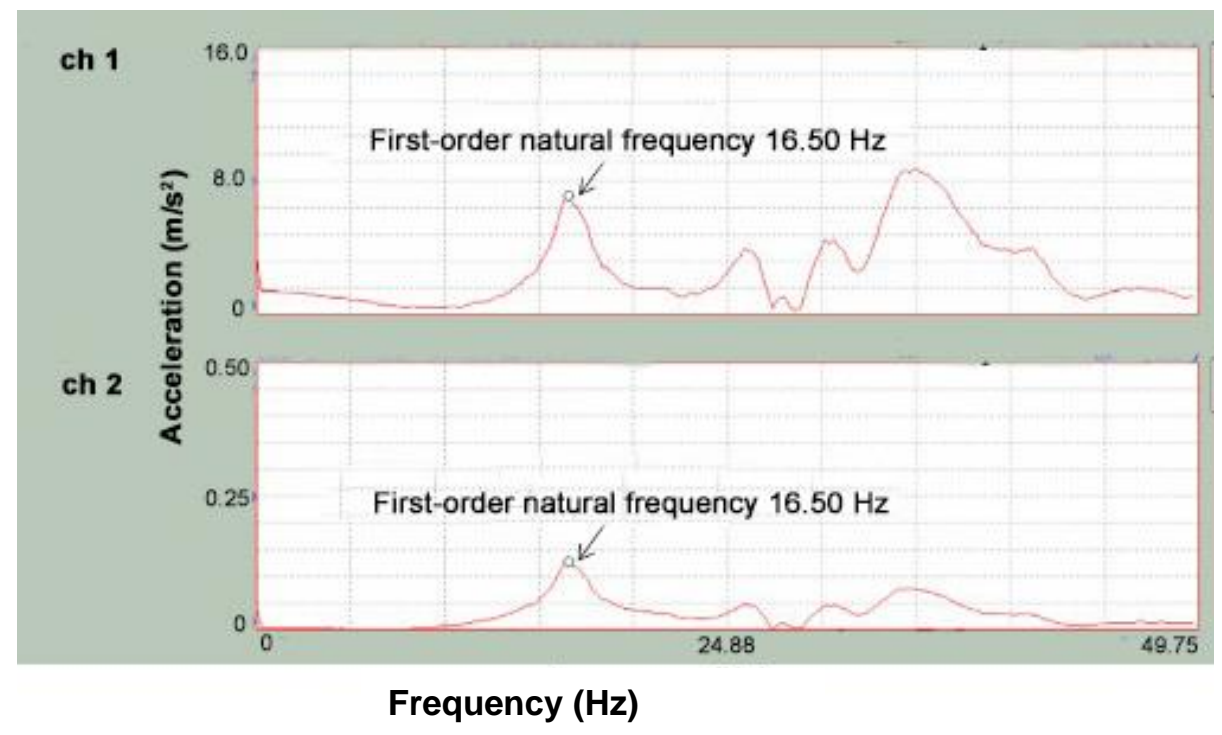

Fig. 7. Spectrum diagram of the single excitation test of a basketball at point 2

(2) Tennis ball single excitation test results

The test results of the acceleration, speed, and frequency values of a single excitation test of a tennis ball at points 1 through 6 are shown in Table 5. 
Table 5. Acceleration, Speed, and Natural Frequency Values of a Single Excitation Test of a Tennis Ball at Points 1 Through 6

\begin{tabular}{|c|c|c|c|c|c|}
\hline & $\begin{array}{c}\text { Acceleration } \\
\text { Peak } \\
\left(\mathrm{mm} / \mathrm{s}^{2}\right)\end{array}$ & $\begin{array}{c}\text { Acceleration } \\
\mathrm{RMS} \\
\left(\mathrm{mm} / \mathrm{s}^{2}\right)\end{array}$ & $\begin{array}{c}\text { Speed } \\
\text { Peak } \\
(\mathrm{mm} / \mathrm{s})\end{array}$ & $\begin{array}{c}\text { Speed } \\
\text { RMS } \\
(\mathrm{mm} / \mathrm{s})\end{array}$ & $\begin{array}{c}\text { Natural } \\
\text { Frequency } \\
(\mathrm{Hz})\end{array}$ \\
\hline Average & 394.6 & 29.11 & 2.548 & 0.163 & 17.06 \\
\hline Maximum & 400.4 & 30.07 & 2.991 & 0.172 & 17.50 \\
\hline $\begin{array}{c}\text { Standard } \\
\text { Deviation }\end{array}$ & 8.74 & 0.85 & 0.35 & 0.01 & 0.37 \\
\hline $\begin{array}{c}\text { Coefficient } \\
\text { of Variation }\end{array}$ & 0.02 & 0.03 & 0.14 & 0.04 & 0.02 \\
\hline
\end{tabular}

(3) Basketball rhythmic excitation test results

The test results of the acceleration, speed, and frequency values of a basketball's rhythmic excitation at points 1 through 6 are shown in Table 6 .

Table 6. Acceleration, Speed, and Natural Frequency Values of Rhythmic Excitation Tests of a Basketball at Points 1 through 6

\begin{tabular}{|c|c|c|c|c|c|}
\hline & $\begin{array}{c}\text { Acceleration } \\
\text { Peak } \\
\left(\mathrm{mm} / \mathrm{s}^{2}\right)\end{array}$ & $\begin{array}{c}\text { Acceleration } \\
\text { RMS }\left(\mathrm{mm} / \mathrm{s}^{2}\right)\end{array}$ & $\begin{array}{c}\text { Speed } \\
\text { Peak } \\
(\mathrm{mm} / \mathrm{s})\end{array}$ & $\begin{array}{c}\text { Speed } \\
\text { RMS } \\
(\mathrm{mm} / \mathrm{s})\end{array}$ & $\begin{array}{c}\text { Natural } \\
\text { Frequency } \\
(\mathrm{Hz})\end{array}$ \\
\hline Average & 282.5 & 35.82 & 1.840 & 0.314 & 16.36 \\
\hline Maximum & 366.5 & 48.55 & 2.418 & 0.413 & 17.00 \\
\hline Standard Deviation & 47.72 & 6.40 & 0.32 & 0.05 & 0.49 \\
\hline $\begin{array}{c}\text { Coefficient of } \\
\text { Variation }\end{array}$ & 0.18 & 0.18 & 0.18 & 0.18 & 0.03 \\
\hline
\end{tabular}

(4) Tennis ball rhythmic excitation test results

The test results of the acceleration, speed, and frequency values of a tennis ball's rhythmic excitation test at points 1 through 6 are shown in Table 7.

Table 7. Acceleration, Speed, and Natural Frequency Values of Rhythmic Excitation Tests of a Tennis Ball at Points 1 Through 6

\begin{tabular}{|c|c|c|c|c|c|}
\hline & $\begin{array}{c}\text { Acceleration } \\
\text { Peak }(\mathrm{mm} / \mathrm{s})\end{array}$ & $\begin{array}{c}\text { Acceleration } \\
\mathrm{RMS} \\
\left(\mathrm{mm} / \mathrm{s}^{2}\right)\end{array}$ & $\begin{array}{c}\text { Speed } \\
\text { Peak } \\
(\mathrm{mm} / \mathrm{s})\end{array}$ & $\begin{array}{c}\text { Speed } \\
\mathrm{RMS} \\
(\mathrm{mm} / \mathrm{s})\end{array}$ & $\begin{array}{c}\text { Natural } \\
\text { Frequency } \\
(\mathrm{Hz})\end{array}$ \\
\hline Average & 399.3 & 69.16 & 4.429 & 0.431 & 16.31 \\
\hline Maximum & 400.1 & 75.29 & 5.536 & 0.529 & 17.00 \\
\hline Standard Deviation & 0.77 & 4.44 & 0.65 & 0.06 & 0.41 \\
\hline Coefficient of Variation & 0.00 & 0.06 & 0.15 & 0.15 & 0.03 \\
\hline
\end{tabular}

\section{Pedestrian Excitation Test Results}

\section{(1) Jump excitation test results}

The test results of the acceleration, speed, and frequency values of the jump excitation test at points 1 through 6 are shown in Table 8 . Figure 8 is the spectrum diagram of the jump excitation test at point 4. 
Table 8. Acceleration, Speed, and Natural Frequency Values of Jump Excitation Tests of a Tennis Ball at Points 1 Through 6

\begin{tabular}{|c|c|c|c|c|c|}
\hline & $\begin{array}{c}\text { Acceleration } \\
\text { Peak } \\
\left(\mathrm{mm} / \mathrm{s}^{2}\right)\end{array}$ & $\begin{array}{c}\text { Acceleration } \\
\text { RMS }\left(\mathrm{mm} / \mathrm{s}^{2}\right)\end{array}$ & $\begin{array}{c}\text { Speed } \\
\text { Peak } \\
(\mathrm{mm} / \mathrm{s})\end{array}$ & $\begin{array}{c}\text { Speed RMS } \\
(\mathrm{mm} / \mathrm{s})\end{array}$ & $\begin{array}{c}\text { Natural } \\
\text { Frequency } \\
(\mathrm{Hz})\end{array}$ \\
\hline Average & 394.9 & 52.35 & 5.571 & 0.804 & 15.67 \\
\hline Maximum & 400.4 & 63.30 & 5.606 & 0.967 & 17.00 \\
\hline Standard Deviation & 5.94 & 10.03 & 0.04 & 0.15 & 0.96 \\
\hline $\begin{array}{c}\text { Coefficient of } \\
\text { Variation }\end{array}$ & 0.02 & 0.19 & 0.01 & 0.19 & 0.06 \\
\hline
\end{tabular}

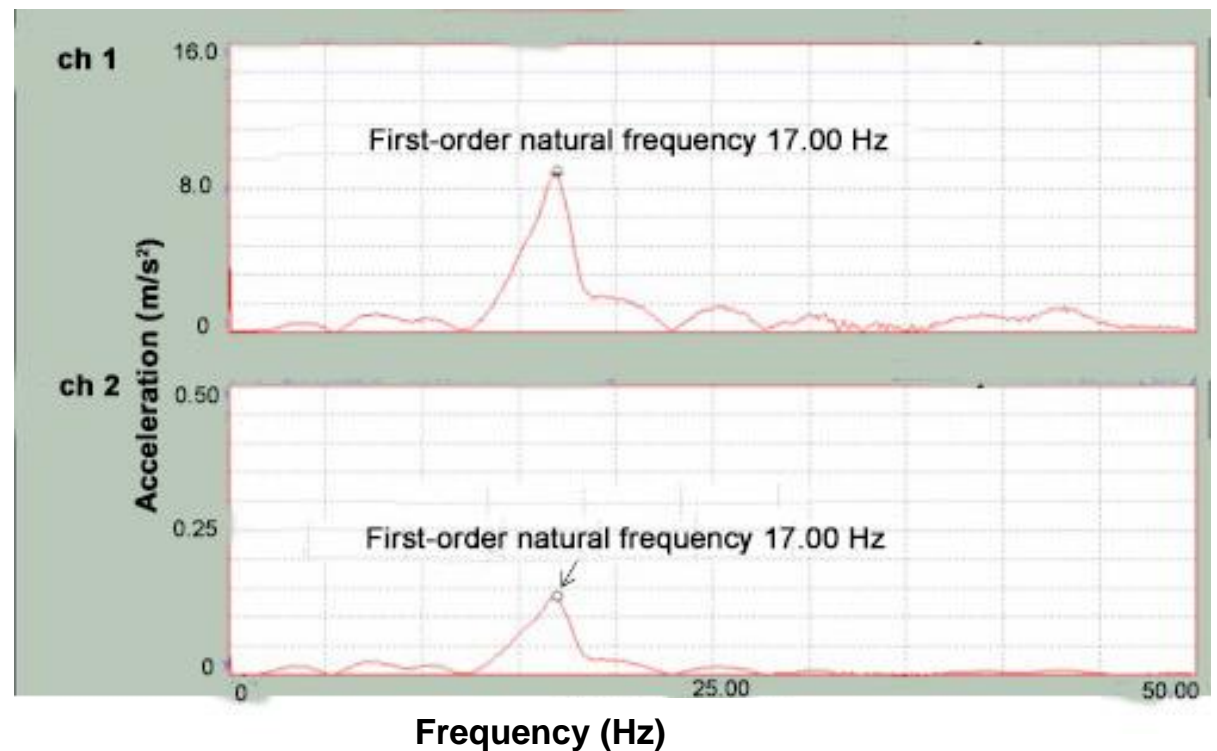

Fig. 8. Spectrum diagram of the jump excitation test at point 4

(2) Single-step excitation test results

The test results of the acceleration, speed, and frequency values of the single-step excitation test at points 1 through 6 are shown in Table 9.

Table 9. Acceleration, Speed, and Natural Frequency Values of Single-step Excitation Tests of a Tennis Ball at Points 1 Through 6

\begin{tabular}{|c|c|c|c|c|c|}
\hline & $\begin{array}{c}\text { Acceleration } \\
\text { Peak } \\
\left(\mathrm{mm} / \mathrm{s}^{2}\right)\end{array}$ & $\begin{array}{c}\text { Acceleration } \\
\mathrm{RMS} \\
\left(\mathrm{mm} / \mathrm{s}^{2}\right)\end{array}$ & $\begin{array}{c}\text { Speed Peak } \\
(\mathrm{mm} / \mathrm{s})\end{array}$ & $\begin{array}{c}\text { Speed } \\
\text { RMS } \\
(\mathrm{mm} / \mathrm{s})\end{array}$ & $\begin{array}{c}\text { Natural } \\
\text { Frequency } \\
(\mathrm{Hz})\end{array}$ \\
\hline Average & 158.9 & 15.80 & 2.180 & 0.206 & 16.95 \\
\hline Maximum & 159.2 & 20.07 & 2.231 & 0.235 & 17.75 \\
\hline Standard Deviation & 0.44 & 2.41 & 0.07 & 0.02 & 0.48 \\
\hline $\begin{array}{c}\text { Coefficient of } \\
\text { Variation }\end{array}$ & 0.00 & 0.15 & 0.03 & 0.10 & 0.03 \\
\hline
\end{tabular}

\section{(3) Steady walk excitation test results}

The test results of the acceleration, speed, and frequency values of steady walking excitation tests at points 1 through 6 are shown in Table 10. Figure 9 is the spectrum diagram of steady walking excitation tests at point 5 . 
Table 10. Acceleration, Speed, and Natural Frequency Values of Steady Walk Excitation Tests of a Tennis Ball at Points 1 Through 6

\begin{tabular}{|c|c|c|c|c|c|}
\hline & $\begin{array}{c}\text { Acceleration } \\
\text { Peak } \\
\left(\mathrm{mm} / \mathrm{s}^{2}\right)\end{array}$ & $\begin{array}{c}\text { Acceleration } \\
\mathrm{RMS} \\
\left(\mathrm{mm} / \mathrm{s}^{2}\right)\end{array}$ & $\begin{array}{c}\text { Speed } \\
\text { Peak } \\
(\mathrm{mm} / \mathrm{s})\end{array}$ & $\begin{array}{c}\text { Speed } \\
\mathrm{RMS} \\
(\mathrm{mm} / \mathrm{s})\end{array}$ & $\begin{array}{c}\text { Natural } \\
\text { Frequency } \\
(\mathrm{Hz})\end{array}$ \\
\hline Average & 357.3 & 60.88 & 2.860 & 0.584 & 16.51 \\
\hline Maximum & 393.0 & 69.36 & 3.320 & 0.692 & 17.00 \\
\hline Standard Deviation & 43.19 & 7.10 & 0.31 & 0.08 & 0.65 \\
\hline $\begin{array}{c}\text { Coefficient of } \\
\text { Variation }\end{array}$ & 0.12 & 0.12 & 0.11 & 0.13 & 0.04 \\
\hline
\end{tabular}

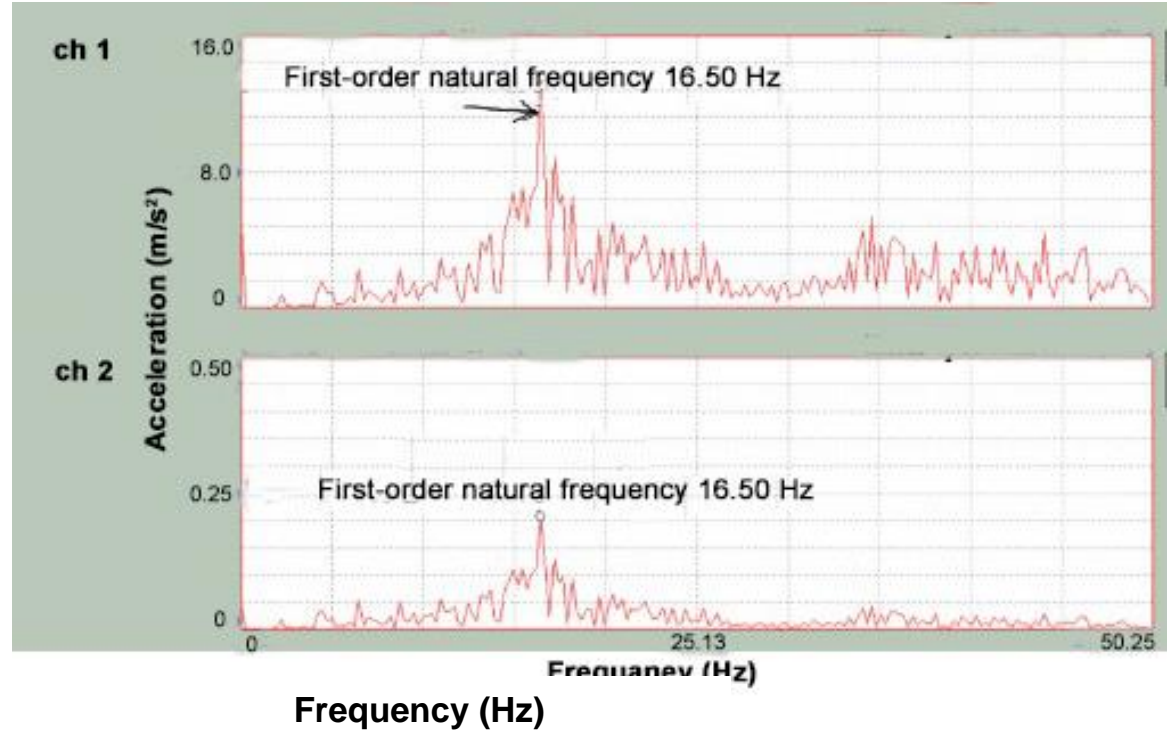

Fig. 9. Spectrum diagram of the steady walkıng excıtatıon test at point 5

(4) Rhythmic running excitation test results

The test results of the acceleration, speed, and frequency values of the rhythmic running excitation at points 1 through 6 are shown in Table 11 .

Table 11. Acceleration, Speed, and Natural Frequency Values of Rhythmic Running Excitation Tests of a Tennis Ball at Points 1 through 6

\begin{tabular}{|c|c|c|c|c|c|}
\hline & $\begin{array}{c}\text { Acceleration } \\
\text { Peak } \\
\left(\mathrm{mm} / \mathrm{s}^{2}\right)\end{array}$ & $\begin{array}{c}\text { Acceleration } \\
\mathrm{RMS}\left(\mathrm{mm} / \mathrm{s}^{2}\right)\end{array}$ & $\begin{array}{c}\text { Speed } \\
\text { Peak } \\
(\mathrm{mm} / \mathrm{s})\end{array}$ & $\begin{array}{c}\text { Speed } \\
\text { RMS } \\
(\mathrm{mm} / \mathrm{s})\end{array}$ & $\begin{array}{c}\text { Natural } \\
\text { Frequency } \\
(\mathrm{Hz})\end{array}$ \\
\hline Average & 336.20 & 58.12 & 3.00 & 0.706 & 15.92 \\
\hline Maximum & 407.20 & 64.87 & 3.90 & 0.100 & - \\
\hline Standard Deviation & 59.06 & 0.09 & 0.33 & 0.140 & 0.78 \\
\hline Coefficient of Variation & 0.18 & 0.575 & 0.11 & 0.636 & 0.05 \\
\hline Remark: "-" is the test value vacancy
\end{tabular}


(5) Floor damping ratio test results

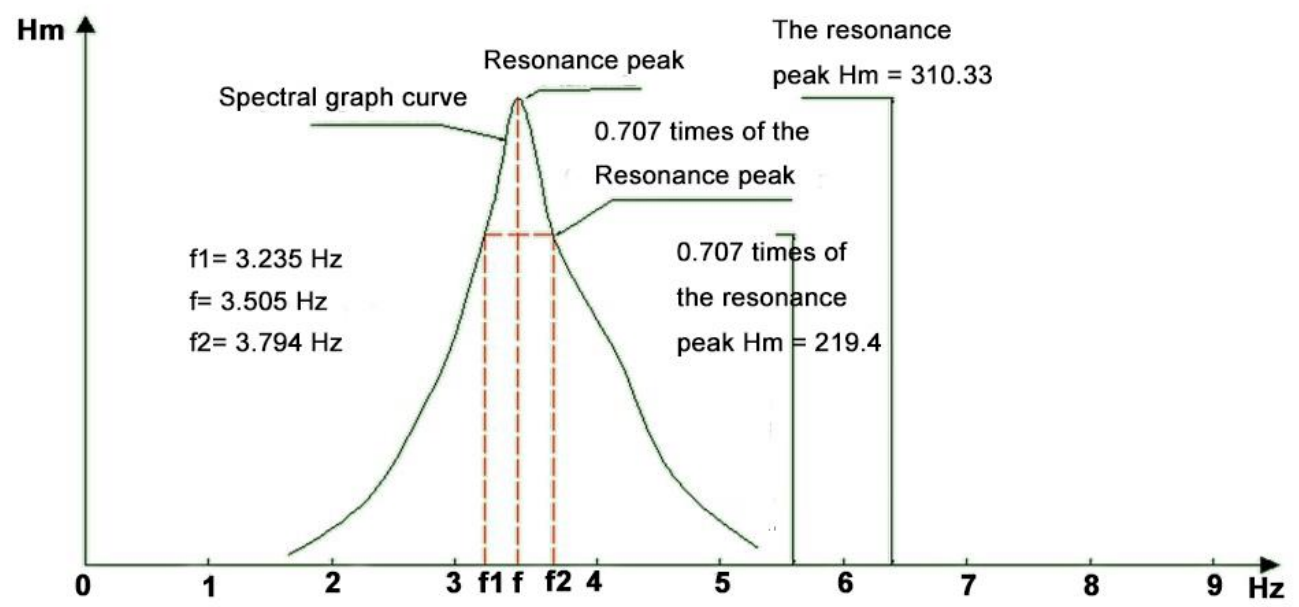

Fig. 10. Frequency spectrum diagram; half power bandwidth calculation damping coefficient

Figure 10 shows the damping ratio test method. The abscissa is the frequency value $(\mathrm{Hz})$, and the ordinate is the amplitude peak $(\mathrm{Hz})$. At the position of 0.707 times of the resonance peak on the resonance curve, a straight line parallel to the frequency axis was made, and it intersected with the resonance curve at two points. The corresponding abscissa values of these two points were $f_{1}$ and $f_{2}$ (Huang 1997; Xu et al. 2008). The damping coefficient can be calculated according to the following half-power bandwidth method of spectrum diagram,

$$
\begin{aligned}
& \xi=\left(f_{2}-f_{1}\right) /(2 f \times 100 \%) \\
& \Delta f=f_{2}-f_{1}
\end{aligned}
$$

where $\xi$ is the damping coefficient, and $f_{1}$ and $f_{2}$ are the values of two intersection points. The measured resonance frequency on the f-spectrum diagram is the natural frequency. This calculation applies to $f<6 \triangle f$. The data were mainly derived from the spectrum of single excitation, such as a basketball, and were exported to Origin Pro software. Subsequently, values of $f_{1}$ and $f_{2}$ were read and $\triangle f$ was calculated, as shown in Fig. 11 . 


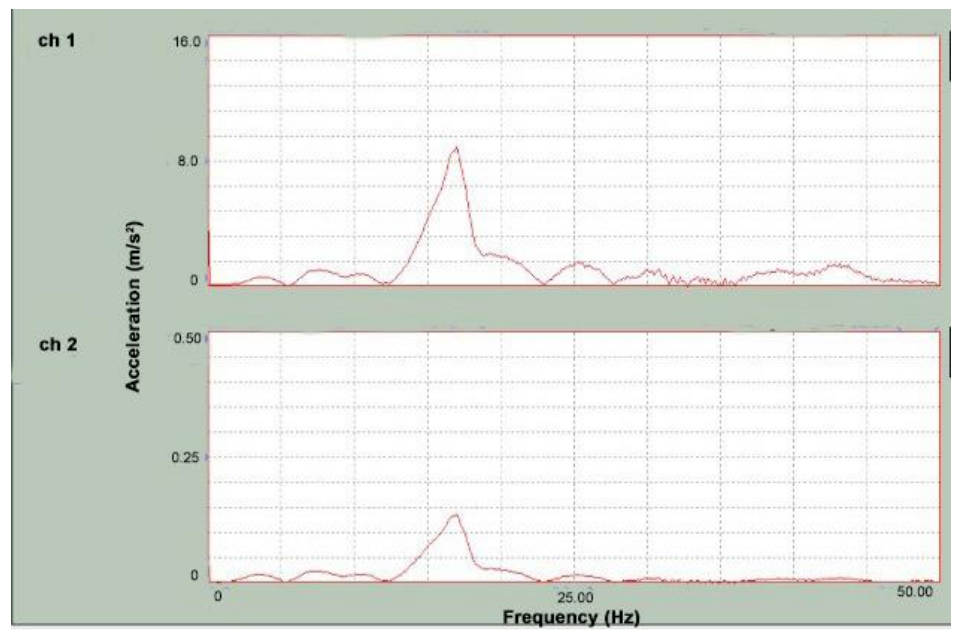

(a) Spectrum diagram in SsCARS

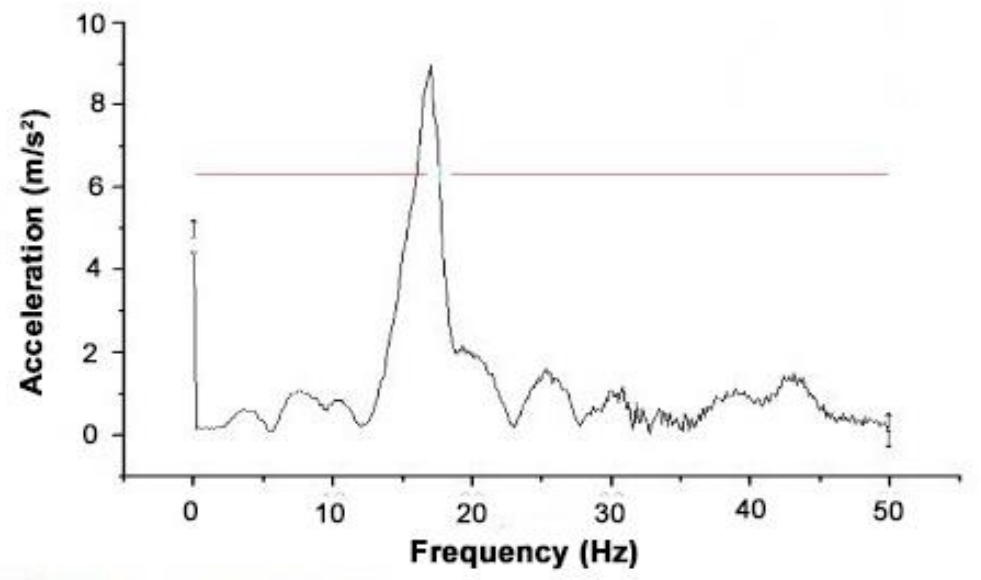

(b) Spectrum diagram in Origin Pro

Fig. 11. Diagram of spectrum diagram conversion

Table 12 shows the damping ratio calculated by a single excitation method. The average damping ratio was $6 \%$.

Table 12. Measured Values of Floor Damping Ratio

\begin{tabular}{|c|c|c|c|c|}
\hline Number & $\begin{array}{c}\text { Natural Frequency } \\
(\mathrm{f} / \mathrm{Hz})\end{array}$ & $f_{1}(\mathrm{~Hz})$ & $f_{2}(\mathrm{~Hz})$ & $\begin{array}{c}\text { Damping Ratio } \\
\xi\end{array}$ \\
\hline 1 & 16.750 & 15.750 & 18.125 & 0.071 \\
\hline 2 & 16.500 & 16.000 & 18.125 & 0.064 \\
\hline 3 & 16.625 & 15.875 & 17.750 & 0.056 \\
\hline 4 & 15.875 & 15.000 & 16.875 & 0.059 \\
\hline 5 & 17.000 & 16.125 & 17.750 & 0.048 \\
\hline 6 & 16.500 & 15.750 & 18.000 & 0.068 \\
\hline 7 & 16.500 & 15.750 & 17.500 & 0.053 \\
\hline 8 & 16.250 & 15.500 & 17.500 & 0.062 \\
\hline 9 & 16.250 & 15.750 & 17.500 & 0.054 \\
\hline Average & - & - & & 0.059 \\
\hline $\begin{array}{c}\text { Standard Deviation } \\
\text { Coefficient of } \\
\text { Variation }\end{array}$ & - & - & & 0.007 \\
\hline
\end{tabular}




\section{Analysis}

Comparison and analysis of finite element simulation results

The fundamental frequency value corresponding to the calculated mode of the floor structure was $16.413 \mathrm{~Hz}$, and the average value of the fundamental frequency of the impact excitation test and the environmental excitation test were $16.41 \mathrm{~Hz}$ and $17.25 \mathrm{~Hz}$, respectively. The calculated modal and experimental modal test results were in good agreement, and the fundamental frequency values are both higher than $4.5 \mathrm{~Hz}$, which meets the requirements of building comfort.

Since the calculation mode is an idealized model, the entire floor is defaulted as a whole, ignoring the joints between materials, and the properties of wood are greatly affected by the environment, and the actual mechanical properties (elastic modulus, Poisson's ratio) may be smaller than the value obtained in the experiment. The measured fundamental frequency differs from the fundamental frequency values of the impact excitation and environmental excitation tests by $0.2 \%$ and $5 \%$, which are basically consistent.

Table 13. Test Results of the First Three-order Natural Frequencies at Different Measuring Points

\begin{tabular}{|c|c|c|c|}
\hline Number & $\begin{array}{c}\text { Mean Natural } \\
\text { Frequency } \\
(\mathrm{Hz})\end{array}$ & $\begin{array}{c}\text { Second Mean Natural } \\
\text { Frequency } \\
(\mathrm{Hz})\end{array}$ & $\begin{array}{c}\text { Third Mean Natural } \\
\text { Frequency } \\
(\mathrm{Hz})\end{array}$ \\
\hline 1 & 17.49 & 26.42 & 34.03 \\
\hline 2 & 17.43 & - & 31.71 \\
\hline 3 & 17.77 & 26.77 & 33.97 \\
\hline 4 & 17.44 & 26.36 & 31.07 \\
\hline 5 & 17.63 & 28.00 & 33.88 \\
\hline 6 & 17.56 & 25.50 & 27.95 \\
\hline \multicolumn{2}{|l}{} \\
\hline
\end{tabular}

Comparison and analysis of environmental excitation test results

Table 13 shows the test results of the first three-order natural frequencies at different measuring points. During the test, the indoor temperature was $15.3{ }^{\circ} \mathrm{C}$, the outdoor temperature was $15.7^{\circ} \mathrm{C}$, and the air humidity was $54 \%$. Figure 12 is a typical spectrum diagram of the six measuring points, and Fig. 13 is a scatter diagram of the first three-order test results under environmental excitation mode.

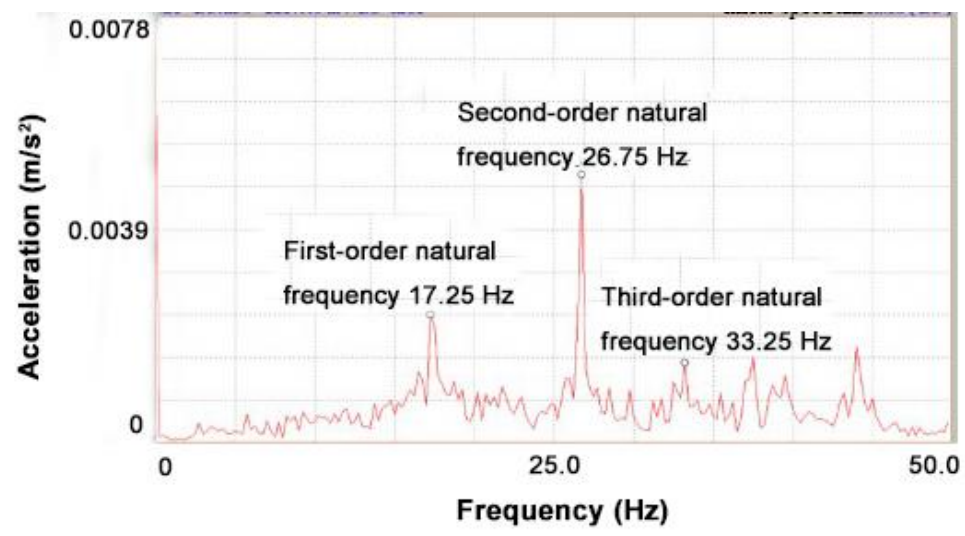

(a) Spectrum diagram of point 1 


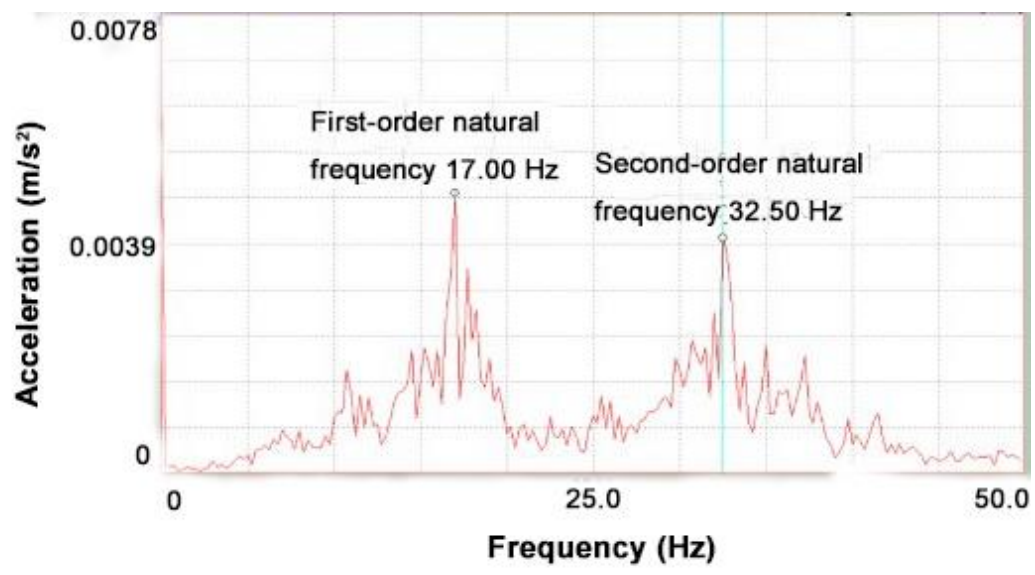

(b) Spectrum diagram of point 2

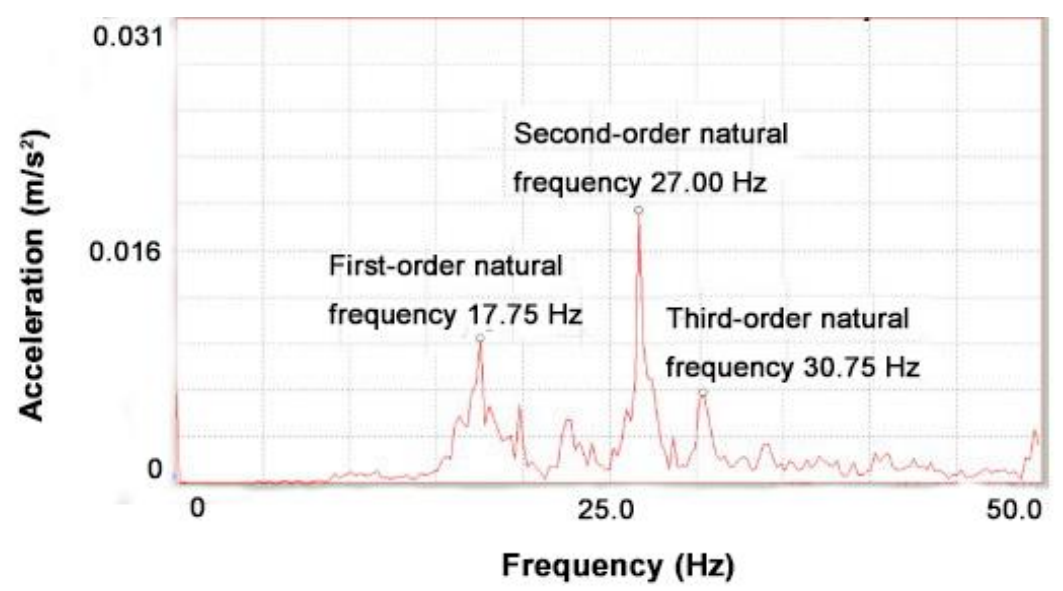

(c) Spectrum diagram of point 3

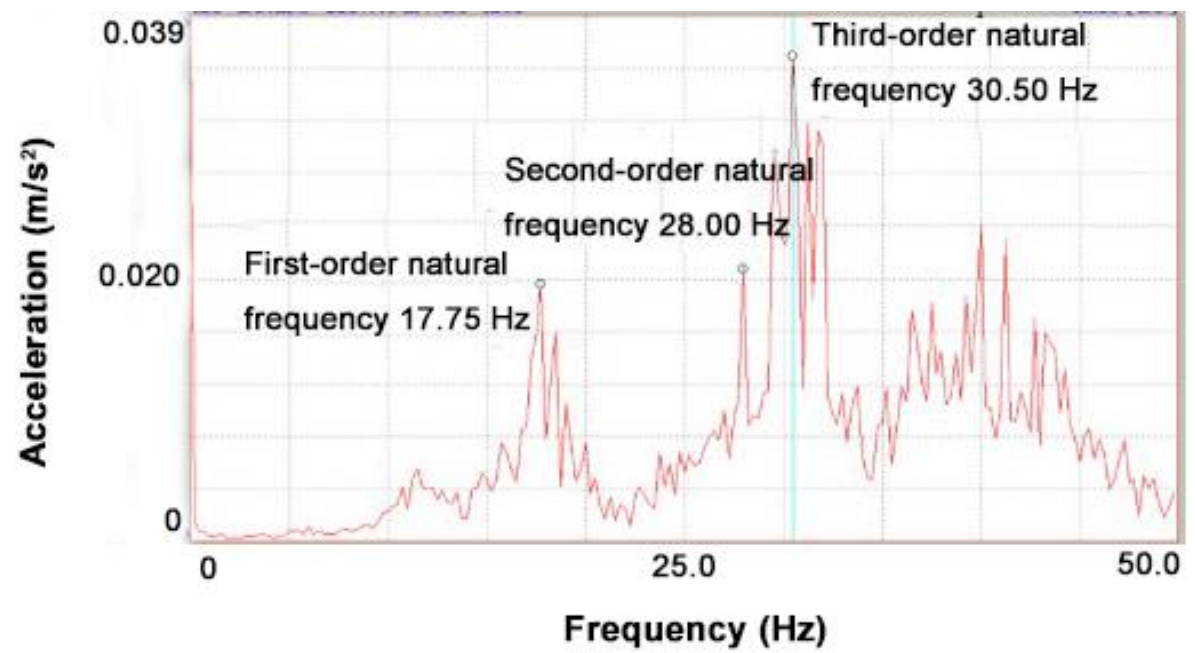

(d) Spectrum diagram of point 4 


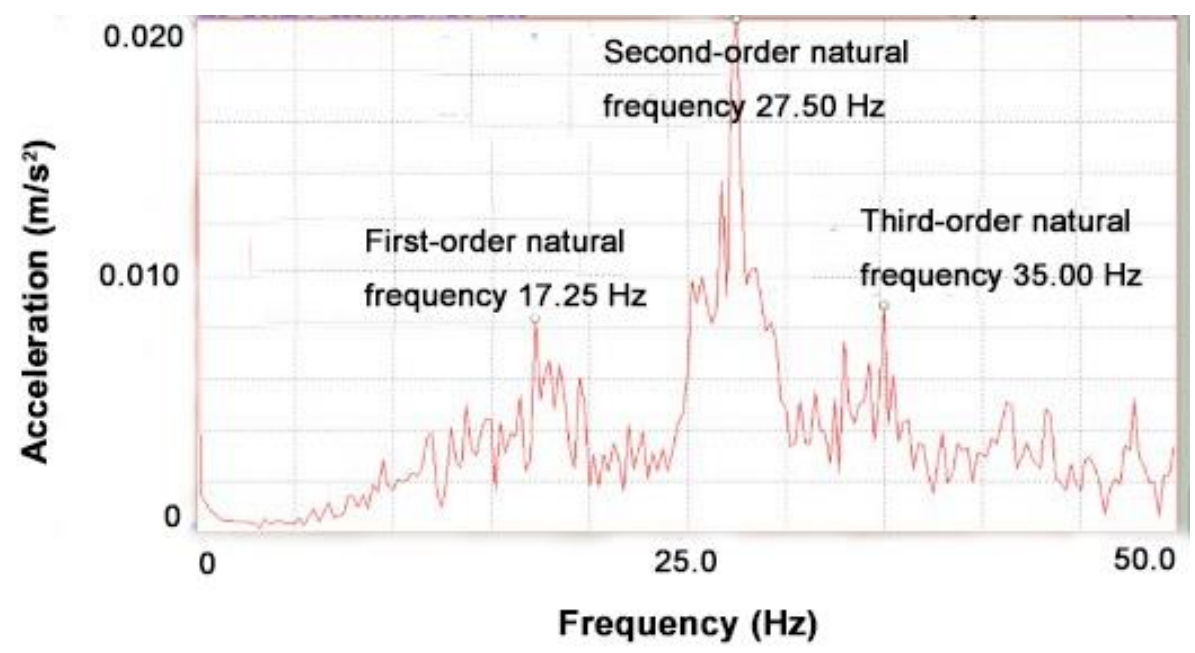

(e) Spectrum diagram of point 5

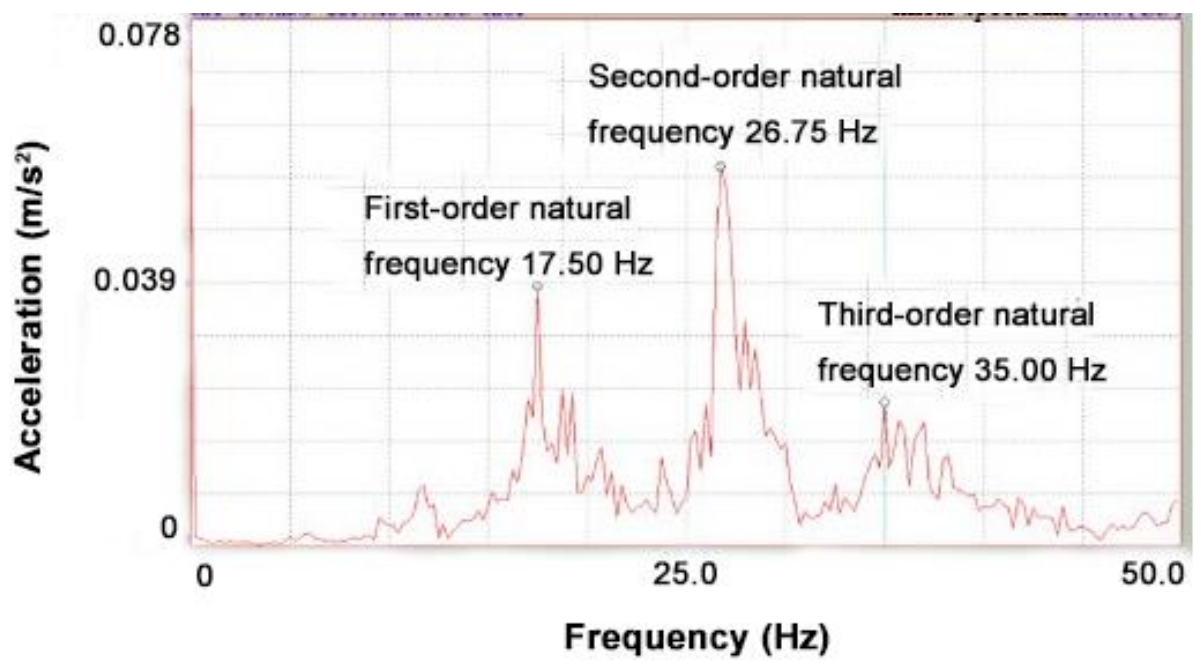

(f) Spectrum diagram of point 6

Fig. 12. Typical spectrum of 6 measuring points 


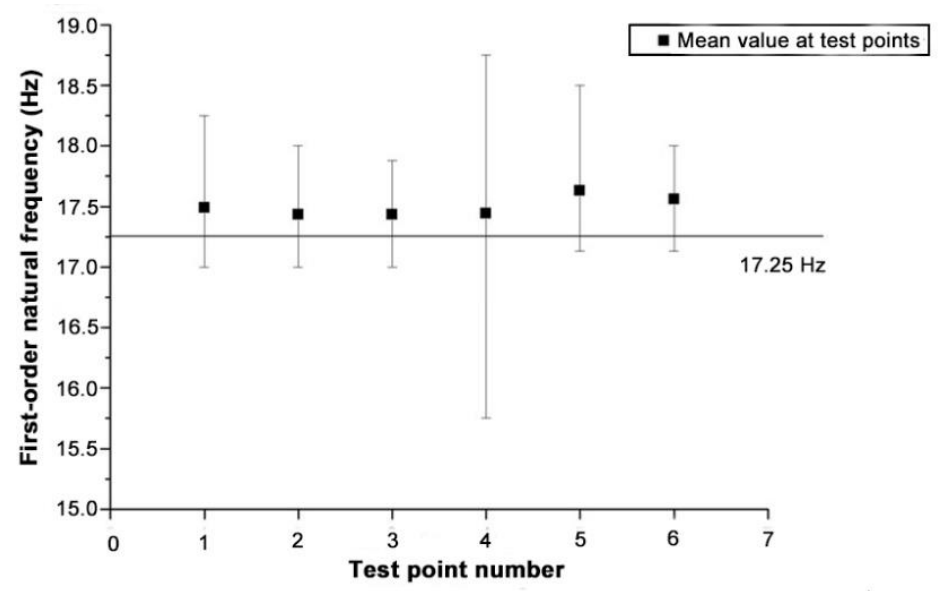

(a) Test frequency diagram of first-order natural frequency

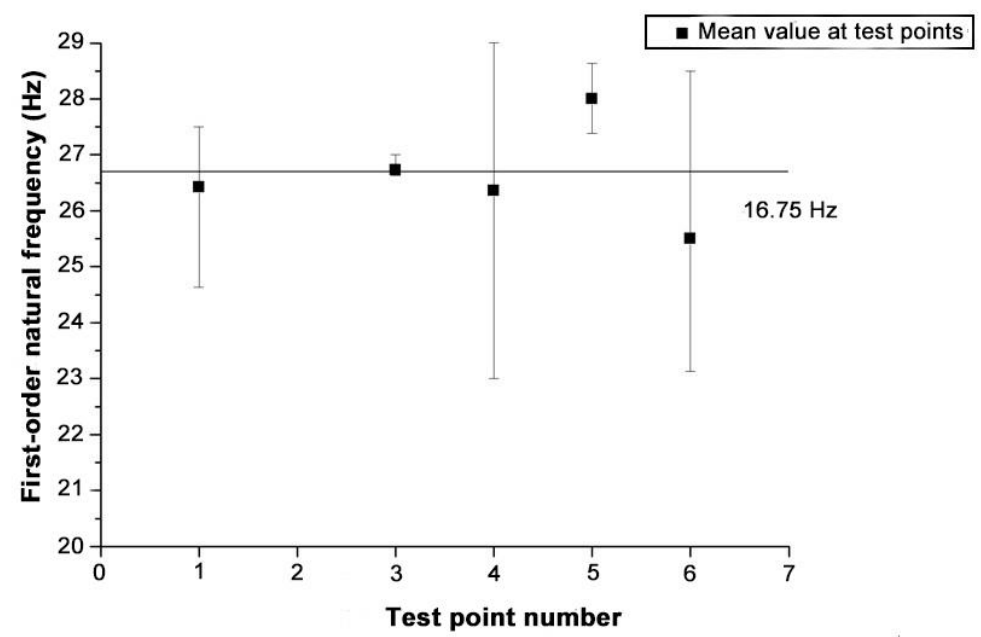

(b) Test frequency diagram of second-order natural frequency

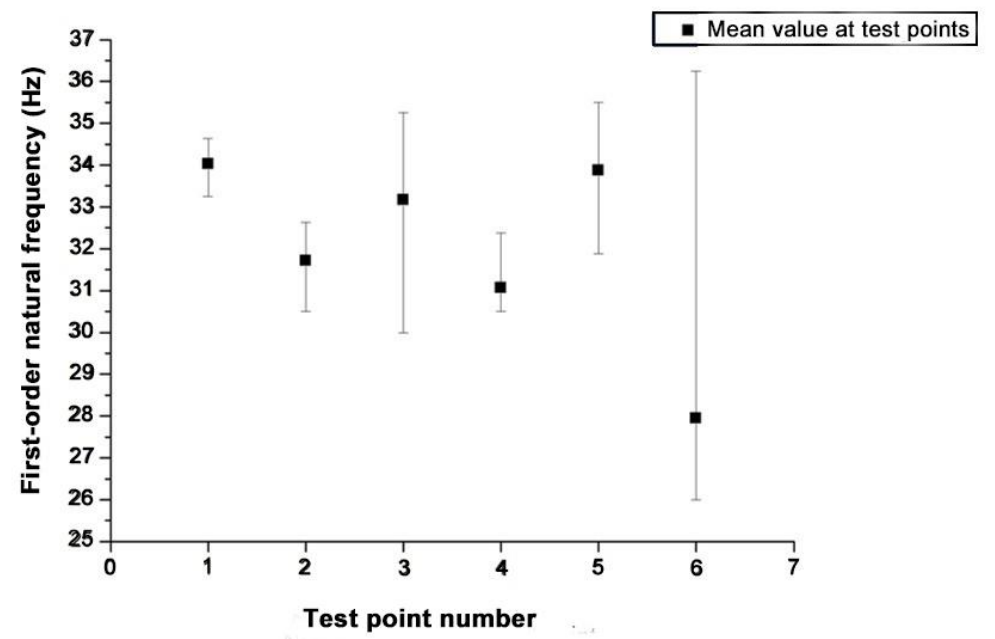

(c) Test frequency diagram of third-order natural frequency

Fig. 13. Scatter diagram of the first three-order test results under environmental excitation 
As shown in Fig. 12, a typical spectrum diagram was selected for the six points' tests. In the test process, from the perspective of spectrum recognition, the test spectrum of points 1,3 , and 6 were more obvious, and thus easily identifiable. The second-order and third-order spectrum of point 4 were not obvious, and the first-order and third-order spectrum of point 5 were not obvious. However, point 2, located at the midpoint of the floor, was at the 0 displacement of the second-order mode.

A scatter diagram with error bars was drawn according to the data in Table 13. Because the conditions of the environmental excitation test were the same as those of modal test, and the modal test frequency was taken as the reference frequency, as shown in Fig. 13. Figure 11a shows that the test accuracy of the first-order frequency of 6 points was ideal, but it should be pointed out that the error of point 4 was large, and the test value of point 3 was the closest to the modal test result. As shown in Fig. 13b, the second-order frequency at point 3 was consistent and the error was minimal. As shown in Fig. 13c, the third-order frequency was not tested under the modal test, so its stability was mainly observed, and the data of point 6 was notably different from the values of the other five points.

Comprehensively considering spectrum identification, data stability, and accuracy, point 3 was the ideal point, and the data of points 1 and 2 were also relatively ideal. It can be seen that the first-order natural frequency measured values for six points were relatively stable, but the first three orders test was relatively stable and reliable for point 3 . Thus, the measuring point should be placed in the stud, avoiding the vibration-shaped nodes such as the $1 / 4,1 / 3$, and $1 / 2$ positions. The test results were clear and accurate. This method can quickly test the natural frequency of the floor, but cannot determine the vibration mode or the damping ratio.

Table 14. Comparison of Test Results of Different Impact Excitation Methods

\begin{tabular}{|c|c|c|c|c|c|c|c|}
\hline $\begin{array}{l}\text { Impact } \\
\text { Form }\end{array}$ & Impact Type & Reference & $\begin{array}{c}\text { Acceleration } \\
\text { Peak } \\
\left(\mathrm{mm} / \mathrm{s}^{2}\right)\end{array}$ & \begin{tabular}{|c|} 
Acceleration \\
RMS \\
$\left(\mathrm{mm} / \mathrm{s}^{2}\right)$
\end{tabular} & $\begin{array}{c}\text { Speed } \\
\text { Peak } \\
(\mathrm{mm} / \mathrm{s})\end{array}$ & $\begin{array}{c}\text { Speed } \\
\text { RMS } \\
(\mathrm{mm} / \mathrm{s})\end{array}$ & $\begin{array}{c}\text { Natural } \\
\text { Frequency } \\
(\mathrm{Hz})\end{array}$ \\
\hline \multirow{6}{*}{$\begin{array}{l}\text { Single } \\
\text { Impact }\end{array}$} & \multirow{2}{*}{ Jump } & Average & 394.9 & 52.3 & 5.571 & 0.804 & 15.67 \\
\hline & & Maximum & 400.4 & 63.3 & 5.606 & 0.967 & 17.00 \\
\hline & \multirow{2}{*}{ Tennis } & Average & 394.6 & 29.1 & 2.548 & 0.163 & 17.06 \\
\hline & & Maximum & 400.4 & 30.1 & 2.991 & 0.172 & 17.50 \\
\hline & \multirow{2}{*}{ Basketball } & Average & 398.9 & 53.9 & 5.542 & 0.629 & 16.53 \\
\hline & & Maximum & 399.1 & 57.0 & 5.545 & 0.676 & 16.75 \\
\hline \multirow{4}{*}{$\begin{array}{l}\text { Multiple } \\
\text { Impact }\end{array}$} & \multirow{2}{*}{$\begin{array}{c}\text { Regular } \\
\text { Basketball }\end{array}$} & Average & 282.5 & 35.8 & 1.840 & 0.314 & 16.36 \\
\hline & & Maximum & 366.5 & 48.6 & 2.418 & 0.413 & 17.00 \\
\hline & \multirow{2}{*}{$\begin{array}{c}\text { Regular } \\
\text { Tennis Ball }\end{array}$} & Average & 399.3 & 69.2 & 4.429 & 0.431 & 16.31 \\
\hline & & Maximum & 400.1 & 75.3 & 5.536 & 0.529 & 17.00 \\
\hline \multirow{4}{*}{$\begin{array}{l}\text { Walk } \\
\text { Impact }\end{array}$} & \multirow{2}{*}{ Tread } & Average & 158.9 & 15.8 & 2.180 & 0.206 & 16.95 \\
\hline & & Maximum & 159.2 & 20.1 & 2.231 & 0.235 & 17.75 \\
\hline & \multirow{2}{*}{$\begin{array}{l}\text { Single Person } \\
\text { Walking }\end{array}$} & Average & 357.3 & 60.9 & 2.860 & 0.584 & 16.51 \\
\hline & & Maximum & 393.0 & 69.4 & 3.320 & 0.692 & 17.00 \\
\hline \multirow{2}{*}{$\begin{array}{l}\text { Rhythm } \\
\text { Impact }\end{array}$} & \multirow{2}{*}{$\begin{array}{c}\text { Single Person } \\
\text { Running }\end{array}$} & Average & 332.2 & 58.1 & 3.137 & 0.706 & 15.92 \\
\hline & & Maximum & 407.2 & 64.9 & 3.850 & 0.854 & 16.75 \\
\hline
\end{tabular}


Analysis of impact excitation test results

Table 14 shows the test results under different impact excitation modes.

At present, there are no Chinese standards specifying the limit value for vibration acceleration and speed of the wooden floor. The research of Huang et al. (2011) shows that when the vibration frequency of floors in offices, residences, and churches is higher than $4.5 \mathrm{~Hz}$, the vibration acceleration peak can usually meet the comfort requirements. The measured fundamental frequency under the environmental excitation mode of the floor structure is between 17.43 and $14.75 \mathrm{~Hz}$, and the measured fundamental frequency under the impact excitation mode is between 15.67 and $17.75 \mathrm{~Hz}$. Both are higher than $4.5 \mathrm{~Hz}$, and thus meet the comfort requirements.

According to the Canadian Standards Council comfort standard (AISC/CISC 1997), for the measured acceleration peak under the impact excitation mode, the floor structure meets the comfort standard requirements because the calculated $a / g$ value is 0.04072 , which is smaller than 0.05 (Fig. 14). Table 15 shows the peaks given by different experiments (Lou 2012). The state of vibration is related to the nature of the vibration source; the natural vibration frequency of the construction structure; the vibration time; the vibration environment; and the state, age, and gender of the person. Therefore, the acceleration peak limit should also be designed and limited according to different objects and different functions. It is known from Tables 14 and 15 that the maximum value of the measured acceleration peak of the floor structure under the impact excitation mode is 407.2 $\mathrm{mm} / \mathrm{s}^{2}$, which is between the comfort state of feeling aware and feeling uncomfortable.

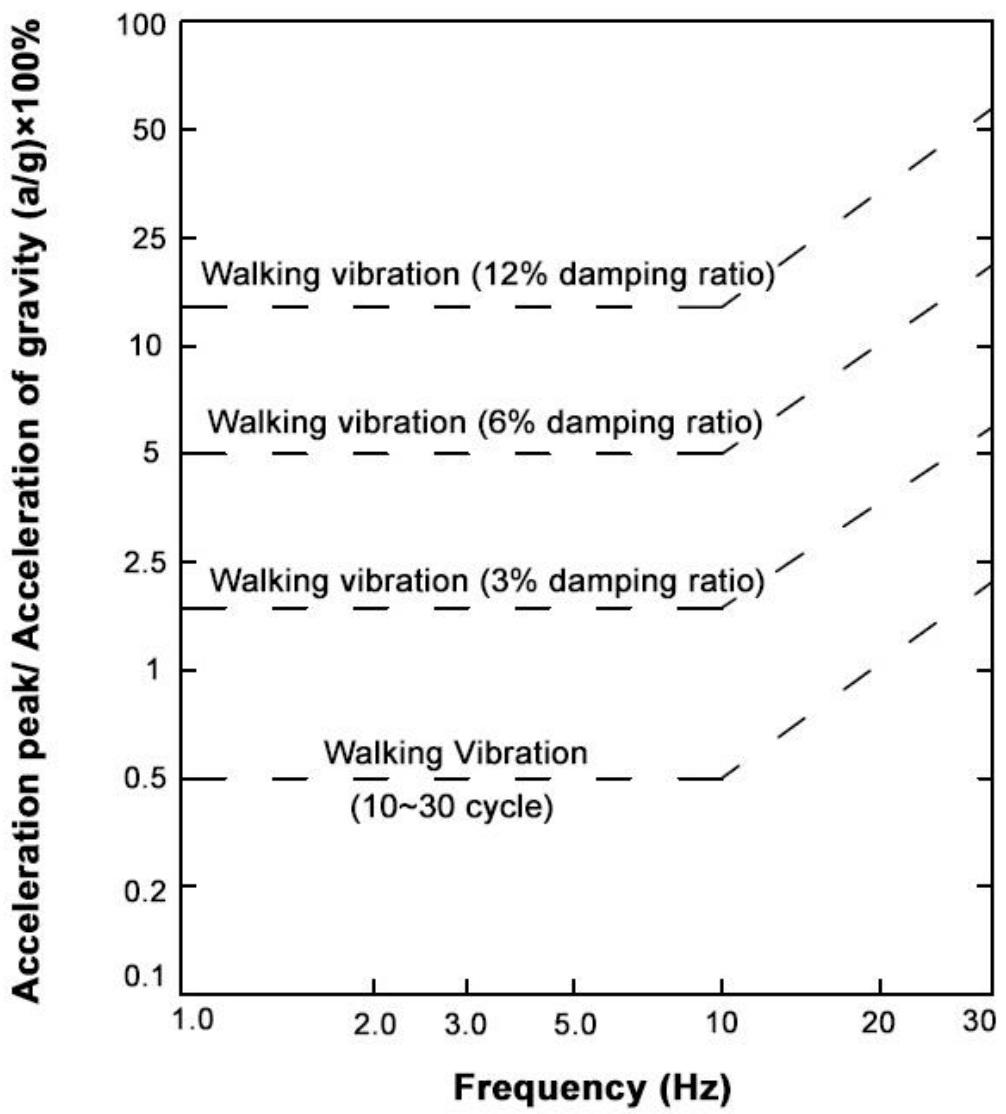

Fig. 14. Canadian Standards Council Comfort Standard 
Table 15. Vibration Comfort Acceleration Peak $\left(\mathrm{mm} / \mathrm{s}^{2}\right)$

\begin{tabular}{|c|c|c|c|c|c|}
\hline Researchers & Comfort & $\begin{array}{c}\text { Can } \\
\text { Feel }\end{array}$ & $\begin{array}{c}\text { Feeling } \\
\text { Aware }\end{array}$ & $\begin{array}{c}\text { Feel } \\
\text { Uncomfortable }\end{array}$ & $\begin{array}{c}\text { Feel } \\
\text { Unbearable }\end{array}$ \\
\hline $\begin{array}{c}\text { Reiher and Meister } \\
(1931)\end{array}$ & $<1.8$ & 12.5 & 110 & 600 & 1000 \\
\hline $\begin{array}{c}\text { Jacklin and Liddell } \\
(1933)\end{array}$ & $<30$ & 30.0 & - & 3000 & 8000 \\
\hline $\begin{array}{c}\text { Helberg and Sperling } \\
(1941)\end{array}$ & $<10$ & - & 220 & - & 800 \\
\hline Lippert (1948) & $<20$ & - & 90 & 250 & 2500 \\
\hline Goldman (1948) & $<60$ & - & - & 1000 & 4000 \\
\hline Dieckmann (1956) & $<30$ & 300 & - & 3000 & - \\
\hline Chang (1973) & $<50$ & $\begin{array}{c}50 \text { to } \\
150\end{array}$ & - & 150 to 500 & $>1500$ \\
\hline
\end{tabular}

For the measured speed peak under the impact excitation mode, Ohlsson (1980) proposed a formula about the speed peak,

$$
v_{\text {peak }}<100 \exp \left[f_{(1)} \xi-1\right] \times 1000 \mathrm{~mm} / \mathrm{s}
$$

where $f_{(1)}$ is the fundamental frequency and $\xi$ is the damping ratio related to $f_{(1)}$. According to Fig. 12, the damping ratio of the floor is selected as $6 \%$ because $v_{\text {peak }}=5.606 \mathrm{~mm} / \mathrm{s}<$ $100 \exp \left[f_{(1)} \xi-1\right]=100 \exp [15.92 \times 0.06-1] \times 1000=902 \mathrm{~mm} / \mathrm{s}$. Clearly, the maximum speed peak value of $5.606 \mathrm{~mm} / \mathrm{s}$ met Ohlsson's theoretical requirements and the comfort requirements.

For the measured effective value of the acceleration under the impact excitation mode, Smith and Chui (1988) proposed the limitation of acceleration effective value (RMS). That is, the frequency weighted root mean square acceleration is less than 450 $\mathrm{mm} / \mathrm{s}^{2}$. The maximum effective value of acceleration (RMS) obtained in this test was 75.3 $\mathrm{mm} / \mathrm{s}^{2}$, which is far less than $450 \mathrm{~mm} / \mathrm{s}^{2}$. Therefore, the wooden floor structure under testing met the comfort requirements.

\section{CONCLUSIONS}

Through the environmental excitation and impact excitation vibration tests and comfort analysis of wooden flooring in a two-story light-wood structure residence, the main conclusions were as follows:

1. The fundamental frequencies of the building structure obtained through the calculation mode and the test mode are consistent, and both are higher than $4.5 \mathrm{~Hz}$, which thus met standard requirements for building comfort.

2. The maximum value of the measured acceleration peak under the impact excitation mode was $407.2 \mathrm{~mm} / \mathrm{s}^{2}$, which is between the comfort state of having awareness of feeling and feeling uncomfortable. The maximum value of the speed peak was 5.606 $\mathrm{mm} / \mathrm{s}$, which met standard requirements for building comfort. The maximum effective value of acceleration RMS was less than $450 \mathrm{~mm} / \mathrm{s}^{2}$, which met the building comfort requirements. The values for fundamental frequency, acceleration peak, and speed peak generally met the people's vibration comfort requirements for wooden floor. 
3. To improve the vibration comfort of the wooden floor, it was necessary to use materials with a high damping ratio during the design, such as filling the Portuguese cork board into the keel of the wooden floor, the floor, and into the OSB board. In the construction, it was necessary to strictly follow the wooden structure design specifications (GB 50005-2017), such as by strictly controlling the selection of, the distance between, and firmness of nails.

\section{ACKNOWLEDGEMENTS}

This study was funded by Co-Innovation Center of Efficient Processing and Utilization of Forest Resources (Nanjing Forestry University, Nanjing 210037, China) and the 2018 Jiangsu Province Policy-oriented North Jiangsu Science and Technology Project (SZ-SQ2018014).

\section{REFERENCES CITED}

CECS 273-2010 (2010). "Code for composite slabs design and construction,” Branch of the Association of Metallurgy of the People's Republic of China, Beijing, China.

Chang, F. K. (1973). "Human response to motion in tall buildings," Journal of the Structural Division 99(6), 1259-1272.

Dieckmann, D. (1956). Die Wirkung Mechanischer Schwingungen (0,5 bis 100 Hertz) auf den Menschen, Springer VS Verlag für Sozialwissenschaften, Wiesbaden, Germany.

GB 50005-2017 (2017). "Standard for design of timber structures," Ministry of Housing and Urban-Rural Development of the People's Republic of China, Beijing, China.

GB 50010-2015 (2015). "Code for design of concrete structures," Ministry of Housing and Urban-Rural Construction of the People's Republic of China, Beijing, China.

Goldman, D. E. (1948). A Review of the Subjective Response to Vibratory Motion of the Human Body in the Frequency Range 1 to 70 Cycles Per Second, U. S. Naval Medical Research Institute, Montgomery, AL, USA.

Helberg, W., and Sperling E. (1941). "Critical appraisal of riding properties of railway vehicles," Fortschr Eisenbahnwesens 96 (12), 2-5.

Huang, B. (1997). "Measurement and analysis of modal damping ratios on tall steel building," Structural Engineers 13(4), 20-24.

Huang, J., Lv, Z. C., and Lou, Y. (2011). "Comfort design of the floor vibration due to rhythmic activities," Special Structures 3, 5-8.

ISO 2631-2 (2003). "Mechanical vibration and shock-Evaluation of human exposure to whole-body vibration-Part 2: Vibration in buildings $(1 \mathrm{~Hz}$ to $80 \mathrm{~Hz})$," International Organization for Standardization, Geneva, Switzerland.

ISO/AWI 2631-1 (1997). "Mechanical vibration and shock-Evaluation of human exposure to whole-body vibration-Part 1: General requirements," International Organization for Standardization, Geneva, Switzerland.

Jacklin, H. M., and Liddell, G. J. (1933). "Riding comfort analysis," Engineering Bulletin Purdue University 17(3), 1-150.

Jarnerö, K., Brandt, A., and Olsson, A. (2015). "Vibration properties of a timber floor assessed in laboratory and during construction," Engineering Structures 82, 44-54. DOI: 10.1016/j.engstruct.2014.10.019 
JGJ 3-2010 (2010). "Technical specification for concrete structures of tall building," Ministry of Housing and Urban-Rural Development of People's Republic of China, Beijing, China.

Li, T. (2012). Vibration Control of the Long-Span Floor Using Tuned Mass Damper, Ph.D. Dissertation, Dalian University of Technology, Dalian, China.

Lin, H. (2015). "Long-span floor design based on comfort," Fujian Architecture \& Construction 7, 30-32.

Lippert, S. (1948). "Comprehensive graph for the collection of noise and vibration data," The Journal of Aviation Medicine 19(4), 279-286.

Lou, Y., Huang, J., and Lv, Z. C. (2012). Vibration Comfort Design of Floor System, Science Press, Beijing, China.

Lu, C. H., Jin, W. L., and Song, Z. G. (2010). "Study on natural frequency of concrete floor based on vibration serviceability," Building Science 26(7), 43-46. DOI: 10.3969/j.issn.1002-8528.2010.07.011

Ohlsson, S. (1980). Floor Vibration and Human Discomfort, Ph.D. Dissertation, Chalmers University of Technology, Gothenburg, Sweden.

Reiher, H., and Meister F. J. (1931). "The sensitiveness of human body to vibrations," Forschung 13(6), 381-386.

Rijal, R., Samali, B., Shresth, R., and Crews, K. (2016). "Experimental and analytical study on dynamic performance of timber floor modules (timber beams)," Construction and Building Materials 122, 391-399. DOI: 10.1016/j.conbuildmat.2016.06.027

Smith, I., and Chui, Y. H. (1988). "Design of lightweight wooden floors to avoid human discomfort," Canadian Journal of Civil Engineering 15(2), 254-262. DOI: 10.1139/188-033

Wang, Z., Fu, H., Ding, Y., Cao, Y., Wang, Y., Wu, X., and Zhang, T. (2019a). "Dynamic testing of shear modulus and elastic modulus of oriented strand board," Scientia Silvae Sinicae 55(8), 136-146. DOI: 10.11707/j.1001-7488.20190815

Wang, Z., Xie, W., Lu, Y., Li, H., Wang, Z., and Li, Z. (2019b). "Dynamic and static testing methods for shear modulus of oriented strand board," Construction and Building Materials 216, 542-551. DOI: 10.1016/j.conbuildmat.2019.05.004

Wang, Z., Xie, W., Wang, Z., and Cao, Y. (2018). "Strain method for synchronous dynamic measurement of elastic, shear modulus and Poisson's ratio of wood and wood composites," Construction and Building Materials 182, 608-619. DOI: 10.1016/j.conbuildmat.2018.06.139

$\mathrm{Xu}, \mathrm{F}$., Li, F., Li, H., and Liu, F. (2008). “A brief discussion on the measurement method of damping coefficient of automotive damping material," Automobile Technology \& Material 8, 63-67.

Yang, X., Tang, X., Ma, L., and Sun, Y. (2019). "Plastic composite sound insulation performance of structural wood wall integrated with wood," Journal of Bioresources and Bioproducts 4(2), 115-122. DOI: 10.21967/jbb.v4i2.197

Zhang, Y., and Xie, L. (2011). Inspection and Evaluation of Wooden Frame Constructions, Chinese Academy of Forestry, Beijing, China. 
Zhou, H. (2006). Studies on Design Methods for Sound Insulation of Wood Structure Walls and Vibration Performance of Wood Structure Floors, Ph.D. Dissertation, Chinese Academy of Forestry, Beijing, China.

Article submitted: June 1, 2020; Peer review completed: August 23, 2020; Revised version received and accepted: September 6, 2020; Published: September 11, 2020.

DOI: $10.15376 /$ biores.15.4.8212-8234 